\title{
Backward associative strength determines source attributions given to false memories
}

\author{
JASON L. HICKS \\ Louisiana State University, Baton Rouge, Louisiana \\ and \\ THOMAS W. HANCOCK \\ University of Georgia, Athens, Georgia
}

\begin{abstract}
Source attributions for falsely remembered material were investigated in two experiments. A male and a female speaker each presented either an entire word list or half of the items from each of multiple Deese-Roediger-McDermott (DRM) lists commonly used in this paradigm. In the latter condition the tendency of each list half to activate a nonpresented, critical list theme item was manipulated. All of the list halves differed in backward associative strength (BAS), and each was presented by one or the other of the two speakers. In these correlated conditions, when critical items were falsely recognized (Experiments 1 and 2) or recalled (Experiment 2), source attributions were more frequently made to the speaker of the list items with the higher average BAS. This source attribution effect appears to result from the binding of list item source characteristics to activated critical items during encoding, as opposed to being the result of a biased retrieval process. The results are interpreted as consistent with an activation/monitoring account of false memory in the DRM paradigm.
\end{abstract}

A considerable amount of research has been conducted recently with the goal of understanding false memory. In particular, semantic knowledge and long-term memory associations have been shown to exert a powerful influence on retrieval from episodic memory (e.g., Anisfeld \& Knapp, 1968; Bower, Black, \& Turner, 1979; Graesser \& Nakamura, 1982; Roediger, Balota, \& Watson, 2001; Underwood, 1965). One striking example of this finding is the tendency of semantic themes in word lists to evoke retrieval of nonpresented information consistent with such themes. Roediger and McDermott (1995) modified a paradigm originally developed by Deese (1959), in which people encode lists of words related to a common, nonpresented theme. For example, if one were to study the list of items nose, breathe, sniff, aroma, whiff, scent, and so on, the probability of falsely recalling or recognizing the critical item smell is quite high. This basic paradigm is now commonly referred to as the Deese-RoedigerMcDermott (DRM, pronounced "dream") paradigm.

Much of the research concerning this paradigm has concentrated on what factors appear to cause or to alter the creation and retrieval of such false memories. However, the present study was motivated primarily by previous work addressing the claims that people make concerning the source (or origin) of their false memories.

The authors thank Jaime Durley and Aaron Kelley for their dedicated help in collecting and scoring the data. Correspondence concerning this article should be addressed to J. L. Hicks, Department of Psychology, Louisiana State University, Baton Rouge, LA 70803-5501 (e-mail: jhicks@1su.edu).
That is, we are interested in the kinds of memorial details people report to be a part of their false memories, especially the aspects concerning their ostensible origin (Johnson, Hashtroudi, \& Lindsay, 1993). Johnson's source monitoring framework has been applied to research concerning people's ability to identify qualitative details found in retrieved memories (e.g., Johnson, Foley, Suengas, \& Raye, 1988). These details can be used to infer the original source (e.g., oneself vs. another) or context (e.g., today vs. 2 days ago) of an experience. For example, retrieving memorial details consistent with imagination, paired with a lack of details specifying perceptual and contextual information, may lead one to infer that a candidate memory has been generated internally as opposed to experienced externally (Johnson \& Raye, 1981). One theory concerning false memory creation that makes source monitoring relevant is the implicit associative response (IAR) hypothesis (Underwood, 1965). Underwood suggested that information is falsely retrieved because that information may reach consciousness at the time when associatively similar information is encoded. According to this hypothesis, people actually encode the critical item from a DRM list, albeit from an internal as opposed to an external source. This idea, in turn, has led to the hypothesis that people could perhaps avoid false memories by more carefully scrutinizing the memorial details found in these memories (e.g., Hicks \& Marsh, 1999, 2001; Mather, Henkel, \& Johnson, 1997; Norman \& Schacter, 1997).

Some of the work on this hypothesis, including our own, has been directed toward understanding what memo- 
rial characteristics are associated with retrieval of the critical items from standard DRM lists (e.g., Hicks \& Marsh, 1999, 2001; Lampinen, Neuschatz, \& Payne, 1999; Marsh \& Hicks, 2001; Payne, Elie, Blackwell, \& Neuschatz, 1996). Interestingly, this research has shown that people are very willing to attribute memorial details characteristic of external presentation to critical items. For example, Payne et al. (1996) demonstrated that people were quite willing to attribute critical items to a male or a female source following repeated recall trials. Even when given a "don't know" option, participants in that study were willing to attribute recalled critical items to a source $87 \%$ of the time. Our own work has compared source retrieval conditions with standard recall or recognition conditions to determine whether source retrieval would reduce the incidence of false memory retrieval. In the case of free recall (Hicks \& Marsh, 1999), asking people to indicate the source of recalled items reduced false recall of critical items, but only when the two sources differed in their memorability.

An interesting pattern of results in the Hicks and Marsh (1999) false recall study was that critical items were consistently attributed to the weaker of the two sources when the sources differed in memorability. When anagrams and heard sources were both used to present items from a given list, falsely recalled critical items were believed to have been heard over $70 \%$ of the time. The same pattern was found when anagrams and seen items constituted the sources. Thus, participants would attribute recalled critical theme words to the weaker source, but were far less willing to report the sort of memorial details that were associated with the stronger source. Similar patterns of source attributions for critical items have been found with standard, recognitionlike source tests (Hicks \& Marsh, 2001). These patterns are reminiscent of the it-had-to-be-you effect in source memory, according to which people are more likely to claim that information has been presented by an external source than experienced internally (Johnson, Raye, Foley, $\&$ Foley, 1981). With regard to false memory research, Schacter and colleagues (e.g., Schacter, Israel, \& Racine, 1999) showed similar effects when DRM list items were experienced in a distinctive format as pictures. Participants in those studies demonstrated lower rates of false memory because they were less willing to claim that critical items were experienced in a memorable format. However, in the Hicks and Marsh studies, source attributions for critical items were balanced when the sources were of equal memorability (e.g., male vs. female).

Hicks and Marsh $(1999,2001)$ argued that source attributions in those studies were likely the result of retrieval factors. Critical items that are retrieved in free recall or considered as test cues in recognition are believed to be old because of the great semantic overlap with other list items (e.g., Arndt \& Hirshman, 1998). Perhaps the true source characteristics associated with list items are imputed to the critical item at retrieval, resulting in the source claims we observed. We find it unlikely that people simply make a guess concerning the origin of the critical items, because studies have shown that people are willing to claim that they do not know the source of critical items only slightly more often than they are willing to claim that they do not know the source of truly studied items (e.g., Hicks \& Marsh, 1999; Lampinen et al., 1999; Payne et al., 1996). Source attributions become unbalanced only when the sources differ in memorability, presumably because of the metacognitive retrieval strategies described in the previous paragraph. Therefore, both sources have an equal probability of being associated with the critical item, and only when other criteria (e.g., source memorability, distinctiveness) are applied do the source attributions become unbalanced.

However, another possibility is that critical items have some probability of being associated with encoding sources by virtue of temporal coregistration with the list items that have activated them. According to the IAR hypothesis, the critical item becomes automatically activated during encoding of the list items and comes to mind as a conscious thought. This activation is likely the result of spreading activation within an associative network (e.g., Gallo, McDermott, Percer, \& Roediger, 2001; Roediger, Balota, \& Watson, 2001). Even if the critical item does not reach consciousness, its activation could nonetheless be associated with the source of the items that have triggered that activation. Thus, characteristics of the encoding context may become associated with the critical item by virtue of the critical item's temporal contiguity with the list item(s) that has (have) activated it. Furthermore, recent work has demonstrated that the associative strength of list items to the critical item (backward associative strength, or BAS) is the strongest predictor of the critical item's false recall (Roediger, Watson, McDermott, \& Gallo, 2001). In this context, BAS is defined as the probability that an item elicits the critical item as a free associate in norming studies. Experimental work has also demonstrated higher levels of false recall and recognition following the encoding of lists with higher total BAS values (McEvoy, Nelson, \& Komatsu, 1999; Robinson \& Roediger, 1997).

Although the aforementioned work has focused on the average BAS of an entire DRM list, each item within a list has its own associated probability of eliciting the critical item in tests of free association (Roediger, Watson, et al., 2001). This raises the possibility that the critical item is activated multiple times during the encoding of a list. We reasoned that correlating DRM list items of different BAS with the source that presents those items should have a measurable effect on the source attributions people will make for critical items that are erroneously recognized or recalled. If the average BAS for half of the list items is higher than that for the other half, the former block of items should have a higher probability of activating the critical item or of eliciting the critical item as an IAR. Therefore, if source characteristics from list items are bound to the critical item at encoding, the source that presents the items with the higher average 
Table 1

Probability of Positive Recognition Responses to Targets and Lures by List Condition in Experiments 1 and 2

\begin{tabular}{|c|c|c|c|c|}
\hline \multirow[b]{3}{*}{ Item Type } & \multicolumn{4}{|c|}{ List Condition } \\
\hline & \multicolumn{2}{|c|}{ Between Lists } & \multicolumn{2}{|c|}{ Within List } \\
\hline & $M$ & $S E$ & $M$ & $S E$ \\
\hline & \multicolumn{2}{|c|}{ Experiment 1} & & \\
\hline \multicolumn{5}{|l|}{ Targets } \\
\hline Strong BAS & .92 & .01 & .87 & .01 \\
\hline Weak BAS & .83 & .02 & .79 & .02 \\
\hline \multicolumn{5}{|l|}{ Lures } \\
\hline Critical & .86 & .03 & .82 & .03 \\
\hline Weak associate & .41 & .02 & .39 & .03 \\
\hline Unrelated & .10 & .02 & .14 & .02 \\
\hline \multicolumn{5}{|c|}{ Experiment 2} \\
\hline \multicolumn{5}{|l|}{ Targets } \\
\hline Strong BAS & .89 & .02 & .89 & .02 \\
\hline Weak BAS & .83 & .02 & .84 & .02 \\
\hline \multicolumn{5}{|l|}{ Lures } \\
\hline Critical & .76 & .04 & .78 & .04 \\
\hline Weak associate & .28 & .03 & .24 & .02 \\
\hline Unrelated & .02 & .01 & .08 & .03 \\
\hline
\end{tabular}

Note-Recognition is inferred for each item type by ignoring the source attribution of male or female. BAS refers to the backward associative strength of list items to the critical item.

BAS should be more likely claimed as the source that presented the critical item when it is falsely retrieved.

To test this hypothesis, we created conditions in which a male and a female speaker each presented half of the items from multiple DRM lists. People encoded the first 14 items in each list, with a male speaker presenting a block of 7 items (i.e., one list half) and a female speaker presenting the other block of 7 items (i.e., the other list half). Using the information in the appendix of Roediger, Watson, et al. (2001), we ensured that the average BAS value of these separate list halves differed. Thus, one source presented a list half of higher average BAS, whereas another source presented items in the weaker list half. This condition was compared with a control condition in which each speaker presented entire lists, instead of only half of the items within a list. We specifically chose both male and female sources because our own past work (Hicks \& Marsh, 1999) has demonstrated equivalent levels of source attributions for critical items when these sources were used within list. If the average BAS of list halves makes no difference, then source attributions to the male and the female speaker will be roughly equivalent regardless of this variable. We also measured source attributions to other nonpresented associates from each list, to compare them with the attributions given to critical items. These manipulations were examined in the context of a standard source test (Experiment 1 ) and in free recall accompanied by source attributions (Experiment 2).

\section{EXPERIMENT 1}

The initial experiment tested source memory for target list items and lures. Six DRM lists were encoded, and select items from each list were used as targets on the source test. Nonpresented test items from each list included the critical item, the 15th list item, and an additional weak associate found in Postman and Keppel's (1970) norms. Semantically unrelated lures were taken from nonstudied DRM lists. To reiterate, our primary interest was in the source attributions given to critical items when they were falsely recognized on the source test.

\section{Method}

Participants. One hundred fourteen undergraduate students participated in partial fulfillment of a course requirement. The conditions were randomly assigned to small-group sessions, with groups comprised of 4 to 10 people. Fifty-two participants were assigned to the control condition and 62 participants were assigned to the experimental condition. Sessions lasted approximately $30 \mathrm{~min}$.

Materials. As in our previous work (Hicks \& Marsh, 1999, 2001; Marsh \& Hicks, 2001), six list themes that produced high levels of false recall in Deese's (1959) original report were used as the primary stimuli. The 15 th item in each list was not presented at encoding, but was reserved for the source test phase. For the encoding phase, videotaped sequences were recorded, in which a male and a female speaker presented the lists. The speakers were taped sitting a few feet apart against a white background. In the betweenlists control condition, each speaker alternated lists by presenting all of the 14 items for a given list. Thus, each speaker presented three of the six lists. A second control tape was created for counterbalancing purposes, on which the speaker and the lists were switched and list order was re-randomized. In the within-list experimental condition, each speaker presented a contiguous block consisting of either the stronger 7 or the weaker 7 items within each 14-item list. The position in which the blocks of items were presented and the speaker who presented each block were also counterbalanced. In other words, the stronger items were presented in Serial Positions 1 through 7 and in Serial Positions 8 through 14 an equal number of times, and by the male and the female sources an equal number of times. Across all six lists, the average BAS for Items 1 through 7 was $.281(S E=.047)$, and for Items 8 through 14 it was $.193[S E=.046, t(5)=4.15]$. Item BAS values were taken from the appendix of Roediger, Watson, et al. (2001). Words from each list were spoken at a 5-sec rate. Sheets of paper containing three-digit multiplication problems were also used by participants during the encoding phase in a distraction exercise.

The source test consisted of selected items from each list and from nonpresented DRM lists. From each list, three stronger associates (Items 2, 4, and 6), three weaker associates (Items 9, 11, and 13), the nonpresented critical item, and two nonpresented weak associates were selected. These nonpresented weak associates were Item 15 from each list plus another drawn from the Postman and Keppel (1970) norms. In addition, 18 unrelated items from other DRM lists were selected, ensuring 36 old and 36 new items on the source test. The test items were printed in a random order in columns on a sheet of paper. Next to each item was a blank line for the source judgment.

Procedure. The participants in each session were told to pay attention to a videotape in which lists of words would be presented. They were told to expect an unspecified memory test. In the control condition, each source alternated in presenting each of the items on the lists, whereas in the experimental condition, each speaker presented a block of half of the items within each list (i.e., the list halves were presented contiguously). After each list was presented, the experimenter paused the videotape and asked the participants to solve a three-digit multiplication problem for $30 \mathrm{sec}$. Following the final distractor period, the experimenter handed out source test sheets face down and provided instructions for the participants. Each item on the test sheet was to be given one of three responses: spoken by the male, spoken by the female, or not pre- 
Table 2

Mean Conditionalized Source Scores for Target Items by List Condition in Experiments 1 and 2

\begin{tabular}{|c|c|c|c|c|}
\hline \multirow{3}{*}{$\begin{array}{c}\text { Source and } \\
\text { Test Item }\end{array}$} & \multicolumn{4}{|c|}{ List Condition } \\
\hline & \multicolumn{2}{|c|}{ Between Lists } & \multicolumn{2}{|c|}{ Within List } \\
\hline & $M$ & $S E$ & $M$ & $S E$ \\
\hline & \multicolumn{4}{|c|}{ Experiment 1} \\
\hline \multicolumn{5}{|l|}{ Male } \\
\hline Strong BAS & .95 & .01 & .67 & .02 \\
\hline Weak BAS & .92 & .02 & .70 & .03 \\
\hline \multicolumn{5}{|l|}{ Female } \\
\hline Strong BAS & .94 & .02 & .69 & .02 \\
\hline Weak BAS & .92 & .02 & .70 & .02 \\
\hline & \multicolumn{4}{|c|}{ Experiment 2} \\
\hline \multicolumn{5}{|l|}{ Male } \\
\hline Strong BAS & .98 & .01 & .89 & .03 \\
\hline Weak BAS & .96 & .01 & .88 & .02 \\
\hline \multicolumn{5}{|l|}{ Female } \\
\hline Strong BAS & .96 & .01 & .87 & .03 \\
\hline Weak BAS & .94 & .02 & .89 & .02 \\
\hline
\end{tabular}

Note-Proportions reflect the number of items attributed to the correct source divided by the number of items given any source attribution (i.e., items deemed old). BAS refers to the backward associative strength of list items to the critical item.

sented (i.e., new). Participants wrote "M," "F," or "N" in the blank next to each test item, in correspondence with their judgments. The instructions emphasized that we did not want them to guess and, when they were uncertain, to call an item new rather than claim it was experienced earlier. Five minutes were allowed for the source test, which was more time than anyone needed to finish.

\section{Results and Discussion}

The probability of a Type I error was set at .05 for all analyses. Results concerning overall inferred recognition will be presented first, followed by source attributions.

Inferred recognition. All items deemed to have been spoken by either source were counted as positive recognition responses, regardless of the accuracy of the source judgment. The top half of Table 1 presents the average proportion of positive recognition responses to the five types of items on the test. The data show a pattern consistent with past reports (e.g., Gallo et al., 2001; Hicks \& Marsh, 2001; Marsh \& Hicks, 2001; Payne et al., 1996; Roediger \& McDermott, 1995), in that recognition of encoded list items and of critical lures was high and at comparable levels. Predictably, nonpresented weak associates were half as likely to be falsely recognized as compared with critical lures, and unrelated lures were falsely recognized the least often. These general patterns were evident for both the between-lists control condition and the within-list experimental condition.

Target and lure items were analyzed separately. A 2 (condition) $\times 2$ (strength) mixed-model analysis of variance (ANOVA) conducted on recognition of studied list items revealed a main effect of strength $[F(1,112)=$ 49.62, $\left.M S_{\mathrm{e}}=.01\right]$, demonstrating better recognition for associatively stronger list items. The between-lists control condition also had a higher recognition hit rate than did the within-list experimental condition $\left[F(1,112)=7.68, M S_{\mathrm{e}}=\right.$
$.02]$, perhaps owing to slightly more source confusions when two speakers were associated with a given list. The interaction was not significant. A 2 (condition) $\times 3$ (item type) mixed-model ANOVA on lure items also demonstrated that the associative strength of lures mattered greatly $\left[F(2,224)=793.61, M S_{\mathrm{e}}=.02\right]$. Critical lures were the most likely to be erroneously recognized, followed by weak-associate lures, and finally by semantically unrelated lures. There was no main effect of condition, nor was there a significant interaction. Because all of these patterns in recognition are as would be expected, our confidence in the source attributions, presented next, is bolstered.

Source attributions. For studied items, source memory was defined as the proportion of items correctly attributed to their source, given that they were inferred as old. This standard metric corresponds to the conditional source identification measure (CSIM). A score above .50 represents above-chance source memory. The top half of Table 2 presents these data for Experiment 1 by condition, source, and associative strength of the item. The data reveal generally higher levels of source memory for the between-lists condition than for the withinlist condition. This impression was confirmed by a 2 (condition) $\times 2$ (source) $\times 2$ (strength) mixed-model ANOVA. The only significant effect was a source-memory advantage for the between-lists condition $[F(1,112)=$ $\left.164.90, M S_{\mathrm{e}}=.04\right]$. This advantage is not surprising, given that in this condition each list had a single source, allowing the list theme to serve as an additional source retrieval cue. The lack of any other effects indicates that source memory was equivalent for both the male and female sources and for both stronger and weaker target items. That is, average BAS did not affect source memory for studied items.

Source attributions were also calculated for critical lures in each condition. For the between-lists control condition, although the critical item was never externally experienced, we considered whether or not the source attribution given to this item was consistent with the source that presented the entire list. Because the list items all came from the same source in this control condition, one might expect source memory for the critical item to be at "above-chance" levels (e.g., Mather et al., 1997). Critical items that were deemed to have been experienced were in fact attributed to the source that presented the associatively related list items. For lists presented by the male, critical items were labeled "male" $95 \%$ of the time. For lists presented by the female, source attributions were to the female speaker $94 \%$ of the time.

In general, the attributions for both critical and lowassociate lure items were not appreciably different for the between-lists versus the within-list conditions. If we ignore the BAS factor and focus on the source attributions for these combined conditions, critical lures were equally likely to be associated with the female $(M=.41$, $S E=.02)$ and the male $(M=.43, S E=.02)$ source $[t(113)<1]$. Source attributions for weak-associate lures were also equally divided as spoken by the male $(M=.20$, 
Table 3

Proportion of Attributions to the Sources That Presented List Halves of Differing BAS for Critical Items and Weak-Associate Lures for the Within-List Conditions of Experiments 1 and 2

\begin{tabular}{|c|c|c|c|c|}
\hline \multirow{3}{*}{$\begin{array}{l}\text { Measure and } \\
\text { Item Type }\end{array}$} & \multicolumn{4}{|c|}{ List Half* } \\
\hline & \multicolumn{2}{|c|}{ Stronger } & \multicolumn{2}{|c|}{ Weaker } \\
\hline & $M$ & $S E$ & $M$ & $S E$ \\
\hline & \multicolumn{4}{|c|}{ Experiment 1} \\
\hline \multicolumn{5}{|l|}{ Recognition } \\
\hline Critical & .48 & .03 & .34 & .03 \\
\hline Weak associate & .18 & .02 & .21 & .02 \\
\hline \multicolumn{5}{|c|}{ Experiment 2} \\
\hline \multicolumn{5}{|l|}{ Recall } \\
\hline Critical & .32 & .04 & .08 & .02 \\
\hline \multicolumn{5}{|l|}{ Recognition } \\
\hline Critical & .59 & .05 & .19 & .03 \\
\hline Weak associate & .10 & .02 & .14 & .02 \\
\hline
\end{tabular}

Note- * refers to the source that presented items of differing mean backward associative strengths (BAS) to the critical item.

$S E=.01)$ or by the female $(M=.20, S E=.01)$ speaker $[t(113)<1]$. Finally, unrelated lures were also attributed equally to the male $(M=.06, S E=.01)$ and to the female $(M=.06, S E=.01)$ speaker $[t(113)<1]$.

Most importantly, the within-list condition allows for the unique comparison of source attributions to critical and weak-associate lures when the source covaried with the average BAS of list half. Table 3 presents the proportion of source attributions given to critical lures and to weak-associate lures as a function of the speaker that presented the stronger or the weaker list half. The data from Experiment 1 in the top portion of the table show that the attributions for critical lures were more often to the source that presented the stronger list associates than to the source presenting the weaker associates $[t(61)=3.0]$. The same effect was not found for weak-associate lures $[t(61)=1.18]$. Thus, male and female attributions were equally likely overall, for both critical lures and weakassociate lures, as described in the previous paragraph, but only critical lures were more often attributed to the source that presented the stronger list items.

We believe that the critical-item attribution effect found for the within-list condition occurred because critical items were activated during encoding of the lists. Moreover, those items within each list that had higher BAS were more likely to have activated the critical item. Critical items may have then come to be associated with the source that had presented these stronger items. In other words, the source that had activated the critical item (or produced the IAR) by virtue of speaking the stronger list items may have had a higher probability of being bound to the critical item. This explanation is not to imply that items in the weaker list half did not activate critical items at all, but merely that they had a lower probability of doing so, and therefore a lower probability of imputing source characteristics to the critical item.

The potential importance of this attribution effect is supported by two other findings in the data. First, par- ticipants were able to identify the source of stronger and weaker list items equally. Therefore, we can discount a metacognitive explanation potentially attributing the bias to differential source memorability of list halves (cf. Hicks \& Marsh, 1999, 2001). Second, no such effect occurred for weak-associate lures that also fit the theme of the list, despite these items' being falsely recognized more often than unrelated lures. Therefore, a simple semantic relationship to the list theme does not cause the attribution effect. The critical item is unique because the probability of its activation is directly linked to list item BAS, and we correlated BAS with the source. Although this is our preferred interpretation, other potential causes of this effect will be considered in the General Discussion section.

\section{EXPERIMENT 2}

We sought to extend the critical-item attribution effect to conditions of free recall. If the effect found in Experiment 1 is an encoding phenomenon, then the source characteristics bound to the critical item should be available during any sort of explicit source-memory test. Free recall has also been used extensively in the DRM paradigm, so we wanted to explore the generality of this effect. Following Hicks and Marsh (1999), we asked participants to recall freely each list after its presentation. Those in the within-list condition were asked to specify the source of each recalled item underneath column headings. The participants in the between-lists condition, of course, did not have to make a source judgment during recall because only one source presented each list. Although the free recall results were of primary interest, exactly the same final source test used in Experiment 1 was also administered after recall of the final list.

\section{Method}

Participants. Sixty undergraduate students participated in partial fulfillment of a course requirement. Thirty participants were randomly assigned to the within-list experimental condition and 30 were assigned to the between-lists control condition.

Materials and Procedure. The materials and procedure from Experiment 1 were used again in Experiment 2. The only difference was the addition of the free recall task. Participants were informed before the experiment began that their recall would be tested following presentation of each list. Special recall packets were provided for this aspect of the procedure. Subsequent to the 30-sec distractor math phase that followed each list's presentation, participants in the between-lists condition were asked to recall freely all of the items that they could from the list. In the within-list condition, items were recalled under column headings specifying each source as male or female. Those participants were asked to recall as many items as possible according to which speaker originally presented the items. This task was similar to the source recall task used in Hicks and Marsh (1999). All participants were asked not to guess. One minute and $45 \mathrm{sec}$ were allowed for recall of each list. The source test used in Experiment 1 was administered after the sixth list was recalled.

\section{Results and Discussion}

Recall of target and lure items. Table 4 contains the average proportion of studied items that were recalled for 
Table 4

Mean Proportion of Correct and Incorrect Source Attributions for Recalled Items by BAS and Condition in Experiment 2

List Condition and Source Attribution

\begin{tabular}{|c|c|c|c|c|c|c|c|c|}
\hline \multirow{4}{*}{$\begin{array}{c}\text { Source and } \\
\text { Test Item }\end{array}$} & \multicolumn{8}{|c|}{ List Condition and Source Attribution } \\
\hline & \multicolumn{4}{|c|}{ Between Lists } & \multicolumn{4}{|c|}{ Within List } \\
\hline & \multicolumn{2}{|c|}{ Male } & \multicolumn{2}{|c|}{ Female } & \multicolumn{2}{|c|}{ Male } & \multicolumn{2}{|c|}{ Female } \\
\hline & $M$ & $S E$ & $M$ & $S E$ & $M$ & $S E$ & $M$ & $S$ \\
\hline \multicolumn{9}{|l|}{ Male } \\
\hline Strong BAS & .74 & .02 & - & - & .70 & .02 & .02 & .0 \\
\hline Weak BAS & .59 & .02 & - & - & .59 & .04 & .03 & .0 \\
\hline \multicolumn{9}{|l|}{ Female } \\
\hline Strong BA & - & - & .74 & .02 & .04 & .01 & .68 & .0 \\
\hline Weak BAS & - & - & .59 & .02 & .01 & .02 & .61 & .0 \\
\hline
\end{tabular}

Note-There were no misattributions for the between-lists condition because only one source presented each list. BAS refers to the backward associative strength of list halves to the critical item.

each list condition. The table also contains the source attributions in the within-list condition. The overall proportion of correct recall for the within-list condition can be inferred by adding together the proportions of items attributed to each source (i.e., across the rows of the righthand portion of the table). There are no misattributions for the between-lists condition because no source judgments were required during recall. Two features of these data are most evident. First, there were very few source attributions during recall for the within-list condition. Thus, no distinction will be made between correct and incorrect attributions in the within-list condition, and only the total proportion of correctly recalled items will be analyzed. Second, items from list halves more strongly associated with the critical item were recalled best. A 2 (condition) $\times 2$ (source) $\times 2$ (strength) mixed-model ANOVA was conducted on these data. There was a main effect of associative strength, demonstrating better correct recall of stronger items $\left[F(1,58)=89.19, M S_{\mathrm{e}}=.01\right]$. No other interesting effects were significant.

Participants in both conditions erroneously recalled an equivalent proportion of critical items. The betweenlists condition $(M=.38, S E=.04)$ was not statistically different from the within-list condition $[M=.40, S E=.05$, $t(58)<1]$. Furthermore, critical items were attributed equally to the male and female sources for both conditions combined $(M=.19, S E=.02$, both to the male and to the female source). However, for the within-list condition alone, the bottom half of Table 3 reveals that recalled critical items were far more often attributed to the source that presented the stronger list half than to the source that presented the weaker list half $[t(29)=5.43]$. This outcome replicates the pattern found in the source test attributions of Experiment 1. Weak-associate lures were never falsely recalled. In the next two sections we report analyses from the final source test administered at the end of the experiment.

Inferred recognition. As in Experiment 1, hit rates to target items and false alarm rates to lure items were calculated. These data are presented in the bottom half of Table $1 .^{1}$ The same pattern for studied items in Experi- ment 1was replicated in this experiment, in that highBAS list items were better recognized than were lowBAS list items. A 2 (condition) $\times 2$ (strength) mixed-model ANOVA confirmed this main effect of item strength $\left[F(1,58)=12.83, M S_{\mathrm{e}}=.01\right]$. The same general pattern also held for lures. False recognition of critical lures was highest, with unrelated false alarms near floor, and false alarms to weak associates roughly in between. A 2 (condition) $\times 3$ (item type) mixed-model ANOVA revealed only a main effect of type of lure item $[F(2,116)=375.58$, $\left.M S_{\mathrm{e}}=.02\right]$. Thus, the patterns found in Experiment 1 were replicated.

Source attributions. Attributions on the final source test are shown in the bottom half of Table 2. Again, the only noticeable pattern in these data was a source memory advantage for the between-lists condition. A 2 (condition) $\times 2$ (source) $\times 2$ (strength) mixed-model ANOVA confirmed this main effect of condition $[F(1,58)=28.68$, $\left.M S_{\mathrm{e}}=.01\right]$. Source attributions for all three types of lures were consistent with the results of Experiment 1. The pattern of attributions to the male and female speakers was very similar for both the between-lists and the within-list conditions. Pooling over the combined conditions and ignoring the BAS factor to examine overall performance, critical lures were attributed to the male source $(M=.41$, $S E=.02)$ and the female source $(M=.37, S E=.02)$ at similar rates $[t(59)=1.47, p>.10]$. There was a slight but nonsignificant tendency for weak-associate lures to be attributed to the male source $(M=.12, S E=.01)$ less often than to the female source $[M=.14, S E=.01, t(59)=$ $1.86, p=.07]$. Regarding unrelated lures, there was no tendency to attribute these items to the male source $(M=$ $.03, S E=.01)$ as opposed to the female source $[M=.03$, $S E=.01, t(59)<1]$.

For the between-lists control condition, source attributions for critical items were again calculated with regard to the source that presented the related list items. When a list was presented by the male speaker and that list's critical item was given a source attribution, that attribution was correct $100 \%$ of the time. Attributions for critical items were similarly high, at $97 \%$, for lists presented by the female speaker. For the more important within-list condition, the source attributions as as a function of the BAS of the list halves are displayed in the bottom half of Table 3 . Mirroring the pattern of recall attributions, critical lures were far more likely to be attributed to the source that presented the stronger list half, whereas attributions for weak associates revealed no such trend. The effect was obviously significant for critical lures $[t(29)=5.83$ ], but no statistical difference was found for the weak-associate lures $[t(29)=1.47]$. Thus, although attributions to the male and female sources were equivalent overall, only the critical lures were attributed to the source that had presented the stronger list half during encoding.

\section{GENERAL DISCUSSION}

By deliberately correlating the source with the BAS of list items, we found an effect in which critical items 
were more often attributed to the source that presented those items of higher BAS. This effect occurred in explicit tests of source memory during both recognition and free recall. One likely cause of this effect is the higher probability of critical-item activation during presentation of list items of greater BAS (Roediger, Balota, $\&$ Watson, 2001; Roediger, Watson, et al., 2001). The source associated with these stronger list items then became associated with the critical item's activation. Although the source characteristics associated with the critical item are probably not as vivid or well specified as they are for studied list items, they are available nonetheless (cf. Norman \& Schacter, 1997). We reiterate that, in the within-list condition, both sources have some probability of being associated with the critical item by virtue of being associated with half of each list. Yet, the items with higher BAS values likely activate critical items to a greater extent, or more often elicit the critical item as an IAR, causing the source of those items to be more often associated with the critical item as well. The same effect was not found for the other list-relevant lures on the source tests, presumably because they were no more and no less likely to be activated by blocks of items that differed in mean BAS. ${ }^{2}$

Although we have focused on a particular encoding explanation for these results, we considered possible retrieval explanations as well. Across both experiments, items of higher average BAS were recognized and recalled at a higher rate than were items of lower average BAS. Participants may have realized the differential memorability of these items and given source judgments to the critical item by virtue of its association to the source that presented the stronger items. This differential memorability might have been noticeable in Experiment 2, when participants' recall of stronger words was better than their recall of weaker words by about one word per list. Regardless, three lines of reasoning argue against this retrieval-based explanation. First, the source memory data for studied items revealed that people had equivalent source information available for items of different average BAS when these items were recognized (Experiments 1 and 2) and when they were recalled (Experiment 2). Item memorability, as defined by inferred recognition and free recall, was reliably different for items of differing strengths, but source memorability was equivalent. We find it difficult to believe that participants would notice this item advantage on the randomizedsource test in Experiment 1 or by virtue of noticing that one more high-BAS item was recalled in Experiment 2. The ceiling levels of source attributions to studied items in the recall data of Experiment 2 also argue against such a retrieval account. Given that participants were making explicit attributions about the source of the items, we believe it unlikely that they noticed any differential source memorability for the two halves of list items. This sort of awareness that item memorability was confounded with speaker memorability would be necessary to inform such a retrieval decision process.
Second, in Experiment 2, of the $60 \%$ of critical items that went unrecalled in the within-list condition, the majority were still attributed to the source that presented list halves of higher mean BAS $(M=.50, S E=.06)$ rather than to the other source $(M=.19, S E=.04)$ on the final source test. (The remaining items were correctly called new.) Thus, although critical items that were recalled might potentially have been attributed to the "stronger" source because one more list item was recalled for that source, this should not have affected the critical items that were not recalled. These items are conceptually similar to the test items in Experiment 1, which were never considered for free recall in the first place. Third, as discussed in the introduction, Hicks and Marsh (1999, 2001) demonstrated that people attribute critical items to the weaker source when the sources differ in memorability. Thus, if participants in the present experiments do make an inference concerning the memorability of the items presented from the two sources, why would they now use such an inference to claim that critical items were associated with the source that presented "stronger," more memorable, list items?

We do admit that one more possibility exists. ${ }^{3}$ One could argue that, instead of retrieving true source information characteristic of a male or a female voice, participants are remembering when the critical item may have occurred. That is, they may remember during which block of a list a particular critical item was activated. The voice judgment may therefore be an inference made at retrieval by comparing the rough temporal position of the critical item with the other list items that were encoded in that block. For example, if one remembers that the critical item occurred in the first half of a list and that the first items in the list were spoken by the male, an inference can be made that the male must have spoken the critical item. Although we have no empirical evidence that people are retrieving temporal characteristics and then making an inference, as opposed to directly retrieving details of voice, we nonetheless present this hypothesis as a potential alternative. However, even this explanation is consistent with the notion that source characteristics-in this case temporal rather than voice characteristics-are being bound to critical items by encoded items of higher BAS.

At a more general level, our results appear to be consistent with an activation/source monitoring theory of false recall in the DRM paradigm (e.g., Gallo et al., 2001; Roediger, Balota, \& Watson, 2001). By this account, false memories occur because of both encoding and retrieval factors. At encoding, critical items from DRM lists are, at the very least, activated in an associative network (e.g., Roediger, Balota, \& Watson, 2001; Seamon, Luo, \& Gallo, 1998), and perhaps aroused into consciousness as an IAR (e.g., McDermott, 1997; Underwood, 1965). Given that activation at encoding is a key mechanism in this theory, source characteristics present during encoding of list items may become bound to nonpresented, but activated, associates. This theory also focuses on retrieval 
processes. At retrieval, the monitoring of memorial characteristics should also affect the incidence of false memories. Our own past work (Hicks \& Marsh, 1999, 2001; Marsh \& Hicks, 2001) has focused on the potential lack of memorial details in critical items as a means of seeing if their incidence can be reduced. Others have applied the same sort of logic (e.g., Dodson \& Schacter, 2001; Israel \& Schacter, 1997; Mather et al., 1997; Norman \& Schacter, 1997; Schacter, Israel, \& Racine, 1999; Smith, Tindell, Pierce, Gilliland, \& Gerkens, 2001). Importantly, although the critical item likely contains many memorial features that are more characteristic of internal generation (Johnson \& Raye, 1981), it also may contain appreciable levels of detail characteristic of actually presented list items (Norman \& Schacter, 1997). We believe that manipulating the BAS of list items can alter the probability that such external-source details are bound to the critical item during encoding (cf. Robinson \& Roediger, 1997).

The other major theoretical explanation for the creation of false memories is the fuzzy-trace theory of Brainerd, Reyna, and colleagues (e.g., Brainerd, Wright, Reyna, \& Mojardin, 2001; Reyna \& Brainerd, 1995). According to this account, two types of memory traces are left following an experience. Verbatim traces represent specific memorial attributes of the original experience, whereas the gist trace represents the meaning of the experience. False memories in the DRM paradigm are thought to occur because of the strong match between critical items and the semantic or thematic gist of the list items. As discussed by Roediger, Watson, et al. (2001), perhaps the mean backward associative strength of a DRM list determines the level of gist produced by the list. By inference, the gist of the stronger half of our lists would be more compelling than the gist produced by the weaker half of our lists. This would imply that two different gist traces are created by each list, one for each block of items differing in mean BAS, and that critical items are more consistent with one gist trace than with the other.

Unfortunately, how the critical item comes to contain memorial details that are more representative of verbatim traces is not well specified by fuzzy-trace theory. However, recent work by fuzzy-trace theorists has focused on how people come to have strong, but illusory, feelings that critical items have been experienced (i.e., "phantom recollection"; Brainerd et al., 2001). This newer work has not yet detailed the mechanism by which specific source characteristics come to be associated with critical lures (although, to date, neither has the activation/ monitoring theory). Regardless, Brainerd et al. characterized the subjective report of external details given to false memories as truly illusory and constructed at test, rather than as being recollections of encoded memorial details. By this account, one would expect random guessing as to the source of a critical item when two sources present an equal number of items differing in mean BAS from a single list.

We have interpreted our data as evidence that the critical items do contain real evidence of the external-source characteristics representative of list items. Admittedly, we have no other direct evidence for such an attribution. Perhaps soliciting people's ratings of various memorial characteristics (Mather et al., 1997; Norman \& Schacter, 1997) could reveal reliable differences in the amount of source information found in critical items. The activation/ monitoring theory would also predict greater priming of critical items in perceptual implicit memory tests when the retrieval context (e.g., voice) is consistent with the perceptual characteristics presumably bound to that critical item at encoding. Neurophysiologicaldata could also provide evidence of neural activation that is consistent with one source or context over another (e.g., visual vs. auditory modality).

On the basis of recent evidence that BAS is an important factor in the incidence of false memories (McEvoy et al., 1999; Robinson \& Roediger, 1997; Roediger, Watson, et al., 2001), we have found a source attribution effect that appears to be mediated by this factor. This study represents an attempt to isolate potential encoding mechanisms related to the source attributions given to false memories, in addition to previous findings that have focused on retrieval mechanisms (e.g., Hicks \& Marsh, 1999, 2001; Lampinen et al., 1999). Our findings point to a set of potential cognitive mechanisms that explains why false memories are often comprised of such compelling contextual detail.

\section{REFERENCES}

ANISFE LD, M., \& KNAPP, M. (1968). Association, synonymity, and directionality in false recognition. Journal of Experimental Psychology, 77, 171-179.

Arndt, J., \& Hirshman, E. (1998). True and false recognition in MINERVA2: Explanations from a global matching perspective. Journal of Memory \& Language, 39, 371-391.

Bower, G. H., Black, J. B., \& Turner, T. J. (1979). Scripts in memory for text. Cognitive Psychology, 11, 177-220.

Brainerd, C. J., Wright, R., Reyna, V. G., \& Mojardin, A. H. (2001). Conjoint recognition and phantom recollection. Journal of Experimental Psychology: Learning, Memory, \& Cognition, 27, 307-327.

DEESE, J. (1959). On the prediction of occurrence of particular verbal intrusions in immediate recall. Journal of Experimental Psychology, 58, 17-22.

Dodson, C. S., \& Schacter, D. L. (2001). "If I had said it I would have remembered it": Reducing false memories with a distinctiveness heuristic. Psychonomic Bulletin \& Review, 8, 155-161.

Gallo, D. A., McDermott, K. B., Percer, J. M., \& Roediger, H. L., III (2001). Modality effects in false recall and false recognition. Journal of Experimental Psychology: Learning, Memory, \& Cognition, 27, 339-353.

Graesser, A. C., \& Nakamura, G. V. (1982). The impact of a schema on comprehension and memory. In G. H. Bower (Ed.), The psychology of learning and motivation (Vol. 16, pp. 59-109). New York: Academic Press.

Hicks, J. L., \& MARsh, R. L. (1999). Attempts to reduce the incidence of false recall with source monitoring. Journal of Experimental Psychology: Learning, Memory, \& Cognition, 25, 1195-1209.

HiCKS, J. L., \& MARSH, R. L. (2001). False recognition occurs more frequently during source identification than during old-new recognition. Journal of Experimental Psychology: Learning, Memory, \& Cognition, 27, 375-383.

Israel, L., \& Schacter, D. L. (1997). Pictorial encoding reduces false recognition of semantic associates. Psychonomic Bulletin \& Review, 4, 577-581.

Johnson, M. K., Foley, M. A., Suengas, A. G., \& Raye, C. L. (1988). Phenomenal characteristics of memories for perceived and imagined 
autobiographical events. Journal of Experimental Psychology: General, 117, 371-376.

Johnson, M. K., Hashtroudi, S., \& Lindsay, D. S. (1993). Source monitoring. Psychological Bulletin, 114, 3-28.

Johnson, M. K., \& RaYe, C. L. (1981). Reality monitoring. Psychological Review, 88, 67-85.

Johnson, M. K., Raye, C. L., Foley, H. J., \& Foley, M. A. (1981). Cognitive operations and decision bias in reality monitoring. American Journal of Psychology, 94, 37-64.

Lampinen, J. M., Neuschatz, J. S., \& Payne, D. G. (1999). Source attributions and false memories: A test of the demand characteristics account. Psychonomic Bulletin \& Review, 6, 130-135.

MARsh, R. L., \& Hicks, J. L. (2001). Output monitoring tests reveal false memories of memories that never existed. Memory, 9, 39-51.

Mather, M., Henkel, L. A., \& Johnson, M. K. (1997). Evaluating characteristics of false memories: Remember/know judgments and memory characteristics questionnaire compared. Memory \& Cognition, 25, 826-837.

McDermott, K. B. (1997). Priming on perceptual implicit memory tests can be achieved through presentation of associates. Psychonomic Bulletin \& Review, 4, 582-586.

McEvoy, C. L., Nelson, D. L., \& Komatsu, T. (1999). What's the connection between true and false memories? The differential roles of interitem associations in recall and recognition. Journal of Experimental Psychology: Learning, Memory, \& Cognition, 25, 1177-1194.

Norman, K. A., \& Schacter, D. L. (1997). False recognition in younger and older adults: Exploring the characteristics of illusory memories. Memory \& Cognition, 25, 838-848.

Payne, D. G., Elie, C. J., Blackwell, J. M., \& Neuschatz, J. S. (1996). Memory illusions: Recalling, recognizing, and recollecting events that never occurred. Journal of Memory \& Language, 35, 261-285.

Postman, L. J., \& KePPel, G. (EDS.) (1970). Norms of word association. New York: Academic Press.

Reyna, V. F., \& Brainerd, C. J. (1995). Fuzzy-trace theory: An interim synthesis. Learning \& Individual Differences, 7, 1-75.

Robinson, K. J., \& Roediger, H. L., III (1997). Associative processes in false recall and false recognition. Psychological Science, 8, 231-237.

Roediger, H. L., III, Balota, D. A., \& Watson, J. M. (2001). Spreading activation and the arousal of false memories. In H. L. Roediger, III, J. S. Nairne, I. Neath, \& A. M. Surprenant (Eds.), The nature of remembering: Essays in honor of Robert G. Crowder (pp. 95-115). Washington, DC: American Psychological Association.
Roediger, H. L., III, \& McDermott, K. B. (1995). Creating false memories: Remembering words not presented in lists. Journal of Experimental Psychology: Learning, Memory, \& Cognition, 21, $803-$ 814.

Roediger, H. L., III, Watson, J. M., McDermott, K. B., \& Gallo, D. A. (2001). Factors that determine false recall: A multiple regression analysis. Psychonomic Bulletin \& Review, 8, 385-407.

Schacter, D. L., IsRael, L., \& Racine, C. (1999). Suppressing false recognition in younger and older adults: The distinctiveness heuristic. Journal of Memory \& Language, 40, 1-24.

Seamon, J. G., Luo, C. R., \& Gallo, D. A. (1998). Creating false memories of words with or without recognition of list items: Evidence for nonconscious processes. Psychological Science, 9, 20-26.

Smith, S. M., Tindell, D. R., Pierce, B. H., Gilliland, T. R., \& GERKENS, D. R. (2001). The use of source memory to identify one's own episodic confusion errors. Journal of Experimental Psychology: Learning, Memory, \& Cognition, 27, 362-374.

UNDERWOOD, B. J. (1965). False recognition produced by implicit verbal responses. Journal of Experimental Psychology, 70, 122-129.

\section{NOTES}

1. The curious reader may wonder how recognition of these items was affected by whether or not the items were previously recalled (i.e., the testing effect). List items and critical items that were previously recalled were also associated with higher recognition rates as compared to items that were not recalled, as in the Roediger and McDermott (1995) report. However, this produced only a main effect that did not influence the primary variables of interest (e.g., patterns of source attributions). We therefore have reported recognition rates and source performance, without regard to which items were recalled.

2. Although we presented blocks of items from one source or another, a strict version of our hypothesis is that the source characteristics from individual list items are taken on by the critical item during encoding. Such a prediction should apply even when list items of differing BASsource combinations are randomly presented, rather than blocked as they were in our study.

3. We thank John Wixted for bringing this issue to our attention.

(Manuscript received June 7, 2001; revision accepted for publication December 17, 2001.) 